UWS Academic Portal

\title{
Effect of nitrogen doping on the electrochemical performance of resorcinol- formaldehyde based carbon aerogels as electrode material for supercapacitor applications
}

Mirzaeian, Mojtaba; Abbas, Qaisar; Gibson, Des; Mazur, Michal

Published in:

Energy

DOI:

10.1016/j.energy.2019.02.108

Published: 15/04/2019

Document Version

Peer reviewed version

Link to publication on the UWS Academic Portal

Citation for published version (APA):

Mirzaeian, M., Abbas, Q., Gibson, D., \& Mazur, M. (2019). Effect of nitrogen doping on the electrochemical performance of resorcinol-formaldehyde based carbon aerogels as electrode material for supercapacitor applications. Energy, 173, 809-819. https://doi.org/10.1016/j.energy.2019.02.108

\section{General rights}

Copyright and moral rights for the publications made accessible in the UWS Academic Portal are retained by the authors and/or other copyright owners and it is a condition of accessing publications that users recognise and abide by the legal requirements associated with these rights. 


\section{Accepted Manuscript}

Effect of Nitrogen Doping on the Electrochemical Performance of ResorcinolFormaldehyde Based Carbon Aerogels as Electrode Material for Supercapacitor Applications

Mojtaba Mirzaeian, Qaisar Abbas, Des Gibson, Michal Mazur

PII: S0360-5442(19)30306-8

DOI: 10.1016/j.energy.2019.02.108

Reference: EGY 14750

To appear in: Energy

Received Date: 19 October 2018

Accepted Date: 14 February 2019

Please cite this article as: Mojtaba Mirzaeian, Qaisar Abbas, Des Gibson, Michal Mazur, Effect of Nitrogen Doping on the Electrochemical Performance of Resorcinol-Formaldehyde Based Carbon Aerogels as Electrode Material for Supercapacitor Applications, Energy (2019), doi: 10.1016/j. energy.2019.02.108

This is a PDF file of an unedited manuscript that has been accepted for publication. As a service to our customers we are providing this early version of the manuscript. The manuscript will undergo copyediting, typesetting, and review of the resulting proof before it is published in its final form. Please note that during the production process errors may be discovered which could affect the content, and all legal disclaimers that apply to the journal pertain. 


\section{Effect of Nitrogen Doping on the Electrochemical Performance of Resorcinol-}

Formaldehyde Based Carbon Aerogels as Electrode Material for Supercapacitor

\section{Applications}

\section{Mojtaba Mirzaeian"1, Qaisar Abbas ${ }^{* 1}$, Des Gibson ${ }^{1}$, Michal Mazur ${ }^{2}$}

\section{Graphical abstract:}

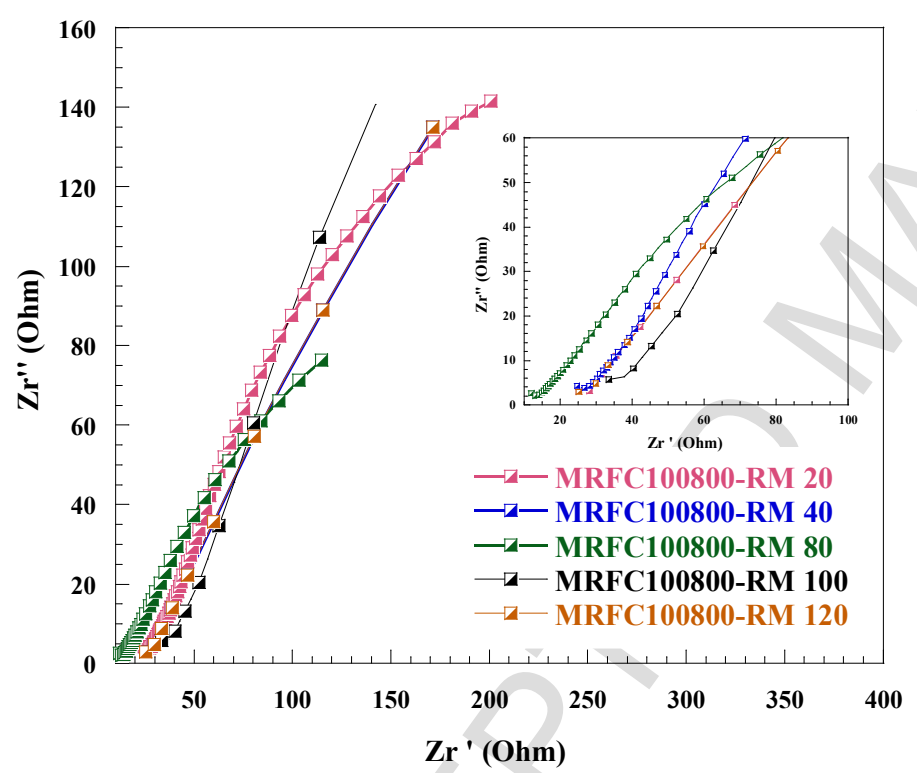

EIS spectra of $\mathrm{N}$-doped carbons with different $\mathrm{R} / \mathrm{M}$ ratios used as the electroactive material in the EC cell

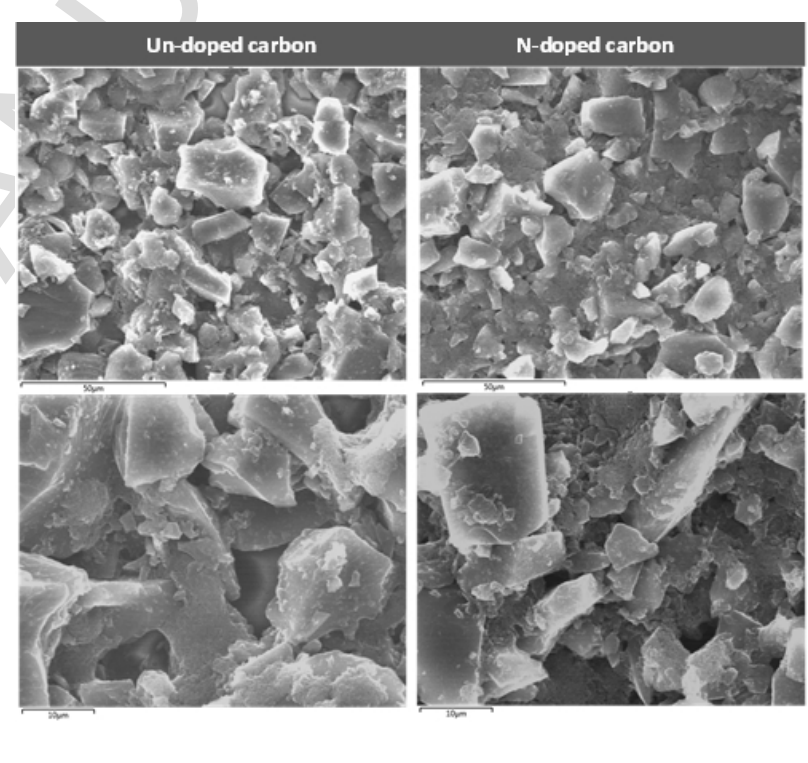

SEM images of un-doped and $\mathrm{N}$-doped carbons at magnifications of 100,50 and $10 \mu \mathrm{m}$.

Dr Mojtaba Mirzaeian

University of the West of Scotland,

School of Computing, Engineering and Physical Sciences

Paisley, PA1 2BE, UK,

Phone: +44(0)141 8483567 ,

Email: mojtaba.mirazeian@uws.ac.uk 


\title{
Effect of Nitrogen Doping on the Electrochemical Performance of Resorcinol-
}

Formaldehyde Based Carbon Aerogels as Electrode Material for Supercapacitor

Applications

\section{Mojtaba Mirzaeian ${ }^{* 1}$, Qaisar Abbas ${ }^{* 1}$, Des Gibson ${ }^{1}$, Michal Mazur ${ }^{2}$}

1- School of Computing, Engineering and Physical Sciences, University of the West of Scotland, Paisley PA1 2BE, United Kingdom.

2- Wroclaw University of Science \& Technology, Faculty of Microsystem Electronics and Photonics, Janiszewskiego 11/17, 50-372 Wroclaw, Poland.

Corresponding authors' e-mail address: mojtaba.mirzaeian@uws.ac.uk, qaisar.abbas@uws.ac.uk

\begin{abstract}
Nitrogen doped resorcinol/formaldehyde carbon aerogels with controlled nitrogen content are synthesized by controlling the resorcinol/melamine molar ratio $(\mathrm{R} / \mathrm{M})$ during the synthesis of aerogel precursors. The carbons were used as electrode materials in an electrochemical capacitor using $6 \mathrm{M} \mathrm{KOH}$ solution as electrolyte. All samples exhibited amorphous structure with low degree of graphitization. The maximum specific capacitance of $208 \mathrm{Fg}^{-1}$ was observed after doping of the carbon with nitrogen at $\mathrm{R} / \mathrm{M}=80$. Drop in solution and charge transfer resistances from $0.57 \Omega$ to $0.15 \Omega$ and $0.05 \Omega$ to $0.04 \Omega$ was also observed respectively, with the drop in contact angles from $123^{\circ}$ to $103^{\circ}$ for the carbon doped with nitrogen at $\mathrm{R} / \mathrm{M}$ $=80$. BET results showed that the pore volume and surface area of carbon increase after Ndoping, with a BET surface area of $841 \mathrm{~m}^{2} \mathrm{~g}^{-1}$ at $\mathrm{R} / \mathrm{M}=80$. This $\mathrm{R} / \mathrm{M}$ ratio is an optimum ratio at which incorporation of nitrogen into the carbon matrix improves the capacitive performance of cell as a result of improved porosity/wettability/conductivity/active sites of the electrode. Doping at higher nitrogen concentrations $(\mathrm{R} / \mathrm{M}<80)$ decreased the specific capacitance of the cell significantly due to decreased conductivity of carbon and suppression of the hopping rate of dopant.
\end{abstract}

\section{Keywords}

Nitrogen doped carbon aerogels, Porous structure, Functional groups, Electrode/electrolyte interface, Electrochemical performance 


\section{Introduction}

Electrochemical capacitors also known as supercapacitors or ultracapacitors are electrical energy storage devices capable of maintaining higher power densities for energy storage applications. However, they retain low energy densities in comparison to other electrical energy storage and conversion devices such as electrochemical batteries and fuel cells respectively [1-5]. Fundamental reason behind their inferior energy densities lies in the charge storage mechanism involved during charging process since the charge is stored in the form of electric double layer at their polarized electrode/electrolyte interface which results in poor capacitive performance and limits their energy storage capability. Lower energy densities limit their engineering applications when requiring both high energy and power densities. Energy density of an electrochemical capacitor as one of its key performance indicators is defined as $\mathrm{E}=\mathrm{C} . \mathrm{V}^{2} / 2$ where $\mathrm{E}$ is the energy density in $\left(\mathrm{Jg}^{-1}\right)$ and $\mathrm{C}$ is the specific capacitance $\left(\mathrm{Fg}^{-1}\right)$ and $\mathrm{V}$ is the operating voltage $(\mathrm{V})$. It can be improved by either enhancing its specific capacitance or maximising its operating voltage. The former depends on the electroactive materials used for the fabrication of electrodes and the latter is related to the use of electrolytes with higher operating voltage. Although a higher operating voltage is only attainable when using non aqueous electrolytes, which in turn results in lower power densities due to diffusional and kinetic problems and increase in equivalent series resistances (ESR) [6].

Different types of materials have been used as electroactive materials for the fabrication of electrodes for electrochemical capacitors. Depending on the charge storage mechanism of the electroactive materials used, electrochemical capacitors are categorised as electric double layer capacitors (EDLCs) and pseudo capacitors (PCs). EDLCs store electric energy as electrostatic charges at the electrode/electrolyte interface in the form of double layer where carbon based materials are mainly considered as the best electroactive materials. Wide ranges of carbon based active materials such as graphene [7], carbon nanotubes [8], carbon fibres [9], carbide derived carbons [10] and carbon aerogel based activated carbons [11-13] have been used owing to their high specific surface area, chemical inertness, control over porosity and excellent electrical conductivity. Due to their versatile form, availability, highly tunable properties, easiness of processing in large scales and also their cost-effective nature, activated carbons are the most preferable electroactive materials used in EDLCs in commercial applications [14]. A comparison between the cost performance of different carbon electrode materials used as electroactive material in EDLCs has shown that cost of electricity storage 
for activated carbons is considerably lower than that for other types of carbons [15]. Zheng et al. have shown that the cost for storing per Wh electricity for activated carbon used as electroactive material in the device is around $2-3 \$ /$ Wh which is significantly lower than $5200-8300 \$ /$ Wh when single wall carbon nanotubes are used as electrode [16]. This makes activated carbons as the electrode materials of choice for EDLC applications.

However, EDLCs suffer from low energy densities in the region of $5 \mathrm{Wh} \mathrm{kg}^{-1}$ [17] as compared to PCs that use metal oxides [18] and conducting polymers [19] as electroactive materials where charge storage on the principle of fast and fully reversible faradic reactions at the electrode/electrolyte interface takes place resulting in energy densities of nearly $40 \mathrm{Wh}$ $\mathrm{kg}^{-1}$ [20]. Different metal oxides such as $\mathrm{AgO}_{2}$ [21], $\mathrm{RuO}_{2}$ [22], $\mathrm{MnO}_{2}$ [23] and $\mathrm{NiO}$ [24] and also conducting polymers such as polypyrrole, polyaniline, and polythiophene based electroactive materials have been used as electrode materials in PCs [25, 26]. Although transition metal oxides and conducting polymer based electrodes improve energy density of the device, however they suffer from elevated cost, poor cycle-ability and inferior electrical conductivity resulting in low power densities. In order to improve the energy density of electrochemical capacitors without scarifying their power density significantly, new electrode materials through the introduction of functional groups such as nitrogen on the surface or into the skeleton of carbon have been synthesized. This results in the improved performance of the device as a result of improved electrode/electrolyte wettability and enhanced electron conductivity of the electrode. It has been shown that due to the electrode donner characteristics of nitrogen atoms, nitrogen doping shifts the Fermi level to the valence band in carbon electrode, and therefore improves the electron transfer processes resulting in improved energy storage capability of the electrode [27-29].

In this study, we report the synthesis of highly porous nitrogen doped carbon aerogels produced by the polycondensation of resorcinol, formaldehyde and melamine followed by carbonization of the resultant gels at elevated temperature under inert atmosphere. Melamine is selected as the source of nitrogen due to its large nitrogen content and high amino group reactivity [30]. This allows the introduction of nitrogen into the bulk of carbon and the control of nitrogen content of the resultant carbon by controlling the molar ratio of resorcinol to melamine $(\mathrm{R} / \mathrm{M})$ during the preparation of the gel precursors. The effect of nitrogen doping on the physical properties of the carbons used as active materials in an EC cell is assessed by different techniques and the electrochemical performance of the cells is investigated by cyclic voltammetry and electrochemical impedance spectroscopy (EIS) measurements. 


\section{Experimental section}

\subsection{Materials}

Resorcinol $\left(\mathrm{C}_{6} \mathrm{H}_{6} \mathrm{O}_{2}\right.$ purity: $\left.99 \%\right)$, Formaldehyde $\left(\mathrm{CH}_{2} \mathrm{O}\right.$ purity: $37 \%$ wt. in $\left.\mathrm{H}_{2} \mathrm{O}\right)$, Sodium Carbonate $\left(\mathrm{Na}_{2} \mathrm{CO}_{3}\right.$ purity: $\left.99.5 \%\right)$, Melamine $\left(\mathrm{C}_{3} \mathrm{H}_{6} \mathrm{~N}_{6}\right.$ purity: $99 \%$ Potassium hydroxide solution (six molar) were purchased from Sigma Aldrich (UK). All chemicals were of analytical grade and used without any further modification during the experiments.

\subsection{Synthesis of resorcinol/formaldehyde $(R F)$ gels}

Resorcinol (R)/Formaldehyde (F) aerogels were prepared by polycondensation reaction between resorcinol and formaldehyde according to the procedure explained elsewhere[31, 32]. Resorcinol (R) and sodium carbonate used as catalyst (C) were mixed in distilled water (W) under vigorous stirring for $45 \mathrm{~min}$ followed by the addition of formaldehyde under continuous stirring for another $45 \mathrm{~min}$ where $\mathrm{R} / \mathrm{C}$ molar ratio was kept at $100 ; \mathrm{R} / \mathrm{F}$ molar ratio was kept at $0.5, \mathrm{R} / \mathrm{W}$ ratio was kept at $0.1 \mathrm{~g} / \mathrm{ml}$ and entire synthesis procedure was performed at room temperature. Prior to placing the homogenous RF solution in the oven, it was transferred into a sealed glass vail to avoid the evaporation of water during the gelation process. Oven temperature was maintained at $25^{\circ} \mathrm{C}$ for the first $24 \mathrm{hrs}$ to allow the initiation of the gelation process followed by increasing it to $60{ }^{\circ} \mathrm{C}$ for $72 \mathrm{hrs}$ and finally to $80{ }^{\circ} \mathrm{C}$ for $48 \mathrm{hrs}$ for the completion of the gelation process. The resultant hydrogel were broken into small pieces and submerged in acetone for 4 days for solvent exchange to replace water with acetone within its structure before drying the gel for 4 days at $64{ }^{\circ} \mathrm{C}$ under vacuum at 5 mbar.

\subsection{Synthesis of nitrogen doped resorcinol/formaldehyde (MRF) gels}

Nitrogen (N) doped resorcinol (R) formaldehyde (F) aerogels were synthesized using melamine as the source of nitrogen. For the preparation of melamine-resorcinolformaldehyde (MRF) gels, a solution was prepared by mixing the predetermine amount of resorcinol and sodium carbonate as catalyst (C) at room temperature. Melamine (M) was then added to the solution and it was heated to $80{ }^{\circ} \mathrm{C}$ and mixed under vigorous stirring for 45 min. The resultant solution was cooled down to room temperature and formaldehyde (F) was added while keeping it under constant stirring for another $45 \mathrm{~min}$. The molar ratios of $\mathrm{R} / \mathrm{F}$ and $\mathrm{R} / \mathrm{C}$ and the ratio of $\mathrm{R} / \mathrm{W}(\mathrm{g} / \mathrm{ml})$ were kept constant at $0.5,100$ and 0.1 respectively whereas the molar ratio of resorcinol to melamine (R/M) was varied between 20 and 120 with the highest nitrogen content at $\mathrm{R} / \mathrm{M}=20$ and the lowest nitrogen content at $\mathrm{R} / \mathrm{M}=120$. The 
same gelation and vacuum drying procedures used for the synthesis of RF gels were adopted for the preparation of MRF gels.

\subsection{Carbonization of $R F$ and MRF aerogels}

Carbonization of the dried RF and MRF aerogels was performed at $800{ }^{\circ} \mathrm{C}$ for $3 \mathrm{hrs}$ to investigate the effect of carbonization on the porosity of carbon aerogels. In each carbonization experiment, $3 \mathrm{~g}$ of a gel sample was placed in a ceramic boat, located in the middle of tubular furnace and purged with argon at room temperature for $30 \mathrm{~min}$ prior to the commencement of heating program. The furnace temperature was increased at the rate of 5 ${ }^{\circ} \mathrm{C} \mathrm{min}{ }^{-1}$ to $150{ }^{\circ} \mathrm{C}$ and held for $30 \mathrm{~min}$. It was further increased to $450{ }^{\circ} \mathrm{C}$ at $5{ }^{\circ} \mathrm{C} \mathrm{min}-1$ and maintained for $30 \mathrm{~min}$. Finally it was heated to the carbonization temperature of $800{ }^{\circ} \mathrm{C}$ at 10 ${ }^{\circ} \mathrm{C} \min ^{-1}$ and kept for $3 \mathrm{hrs}$. After carbonization, the furnace was cooled down to room temperature. All heating and cooling steps were performed under Ar flow at a flowrate of 240 $\mathrm{ml} \mathrm{min}{ }^{-1}$.

\subsection{Electrode fabrication}

Electrochemical capacitor cell electrodes were fabricated using, carbon (un-doped/N-doped) as active material, Kynar 2801 as a binder and Cabot carbon black as the conductivity enhancer in a weight ratio of 80:10:10 respectively. A uniform paste was produced by mixing the electrode constituents in acetone for 2 hrs under magnetic stirring. The paste was then rolled into a thin sheet on aluminium foil with a wet film thickness of approximately 500 micrometres using an applicator. Electrodes in the form of circular disks with the diameter of $1.33 \mathrm{~cm}$ were cut-off using a puncher. They were then dried in a vacuum oven overnight at $85{ }^{\circ} \mathrm{C}$ resulting in dry electrodes with a thickness in the range of about $100-150$ micrometres.

\subsection{Electrochemical capacitor cell assembly}

A two-electrodes symmetrical cell was constructed using the fabricated carbon (un-doped/Ndoped) electrodes with aluminium foil and glass microfiber used as current collector and separator respectively as shown in Figure 1. 


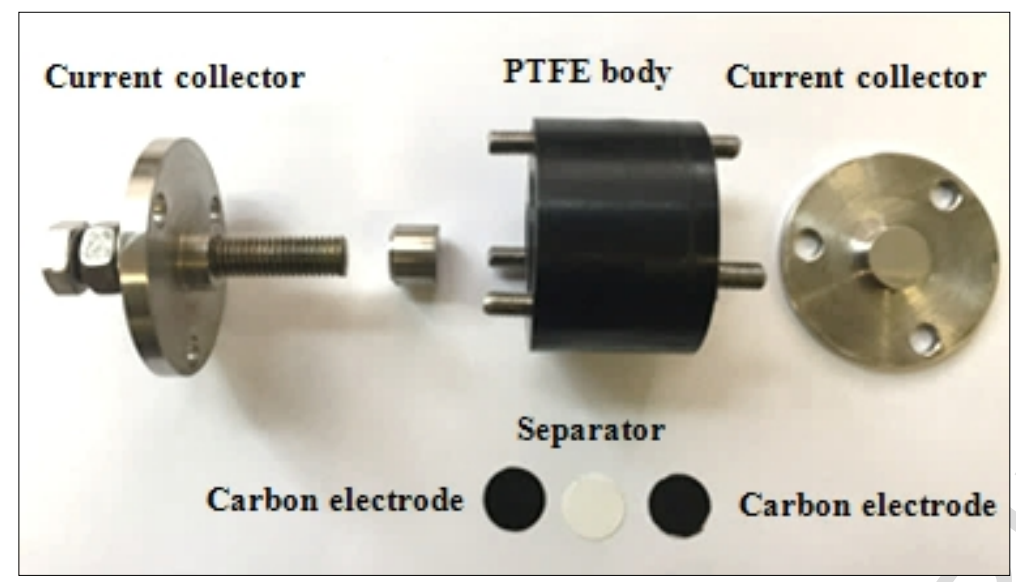

Figure 1: Schematic of the electrochemical capacitor test cell.

Electrolyte comprising of potassium hydroxide aqueous solution (6M) was added to the separator before placing it in the middle of two electrodes. The assembled cell was then placed in low vacuum of $600 \mathrm{mbr}$ for $20 \mathrm{~min}$ to ensure the diffusion of electrolyte in the porous structure of electrodes prior to the electrochemical measurements.

\section{Characterization}

BET measurements: The porosity of the un-doped and $\mathrm{N}$-doped carbon aerogels was characterized by the analysis of nitrogen adsorption-desorption isotherms measured by a Tristar adsorption analyser (Micrometrics) at $77 \mathrm{~K}$. Prior to the adsorption/desorption measurements, all samples were evacuated at $80{ }^{\circ} \mathrm{C}$ under a high vacuum of around $5 \mathrm{mbr}$ in a vacuum oven overnight followed by further $2 \mathrm{hrs}$ purging under nitrogen environment at $300{ }^{\circ} \mathrm{C}$ in a Flowprep system (Micrometrics). Breneur Emmett Teller (BET) equation was used for surface area determination whereas t-plot and Barett Joyner Helda (BJH) methods were used for micropore analysis and mesopore analysis respectively. The total pore volume was calculated from the adsorbed volume of $\mathrm{N}_{2}$ at $\mathrm{P} / \mathrm{Po}=0.99$ [26, 33]. Pore size distributions were obtained by the $\mathrm{BJH}$ method from the adsorption branch of the isotherms [22].

$X R D$ measurements: X-ray diffraction (XRD) measurements were performed using an X-ray diffractometer (SIEMENS - D5000) with the current and voltage kept at $30 \mathrm{~mA}$ and $40 \mathrm{kV}$ respectively to analyse the crystal structure of un-doped/N-doped carbon aerogels.

XPS analysis: To quantitatively analyse the elemental composition of carbon aerogel samples, X-Ray Photoelectron Spectroscopy (XPS) was used with the help of a Specs Phoibos 100 MCD-5 (5 single channel electron multiplier) hemispherical analyser employing 
a Specs XR-50 X-ray source with $\mathrm{Mg} \mathrm{K \alpha}(1253.6 \mathrm{eV})$ beam. All spectra were calibrated with respect to the binding energy of adventitious $\mathrm{C} 1 \mathrm{~s}$ peak at $284.8 \mathrm{eV}$. Measurements results were analysed using the Casa XPS software.

Contact angle measurements: A CAM 200 goniometer system (KSV Ltd) based on video captured images and automatic image analysis using CAM software was used to carry out contact angle measurements. A $6 \mathrm{M} \mathrm{KOH}$ aqueous solution was used as a probing liquid for the determination of contact angles.

Microstructural analysis: The surface morphology/structural properties of the samples were characterized by scanning electron microscopy where the SEM micrographs were obtained by a Hitachi S-4100 SEM at the magnifications of 100, 50 and 10 micrometres.

Electrochemical measurements: The electrochemical performance of all carbon samples was analysed by using them as electroactive materials in the electrodes used in a sandwich type symmetric electrochemical cell with $6 \mathrm{M} \mathrm{KOH}$ solution used as the electrolyte. Electrochemical measurements of the EC cell were carried out by cyclic voltammetry $(\mathrm{CV})$ measurements in potential range of 0.5 to $1.0 \mathrm{~V}$ at scan rates of 5,10 and $15 \mathrm{mVs}^{-1}$, and electrochemical impedance spectroscopy (EIS) measurements were carried out at AC amplitude in the frequency range of $100 \mathrm{KHz}$ to $50 \mathrm{~Hz}$ using a VoltaLab 40 PGZ301potentiostat (Radiometer analytical) with the Voltamaster-4 software for data acquisition and analysis. All electrochemical measurements were carried out at room temperature.

Specific capacitance of the cell was calculated from the discharge curve of CV tests using the following equation;

$$
C=I / d V / d t)
$$

Where ' $\mathrm{I}$ ' is the average discharge current $(A)$ and $\mathrm{dV} / \mathrm{dt}$ is the scan rate $\left(\mathrm{mVs}^{-1}\right)$.

Therefore the specific capacitance of a single electrode, Csp, in $\mathrm{Fg}^{-1}$ was calculated by:

$$
C_{s p}=2 \times{ }^{C} / m
$$

Where ' $\mathrm{m}$ ' is the mass of active material in each electrode. 


\section{Results and discussion}

\subsection{Physical and chemical characterization}

4.1.1 BET analysis of the un-doped carbon aerogel and nitrogen doped carbon aerogels (with different level of nitrogen doping)

Figure 2 shows $\mathrm{N}_{2}$ adsorption-desorption isotherms of un-doped carbon aerogel (RFC100800) and nitrogen doped carbon aerogels with different R/M ratios (MRFC100800$\mathrm{RMx}$ ) where 100 shows the $\mathrm{R} / \mathrm{C}$ ratio, 800 shows the carbonization temperature and $\mathrm{x}$ shows the $\mathrm{R} / \mathrm{M}$ molar ratio used for the preparation of the nitrogen doped carbon aerogels. A significant increase in the volume of gas intake by the samples at low relative pressures of $\mathrm{P} / \mathrm{P}_{0}<0.2$ shows the development of microporosity in the samples with increasing $\mathrm{R} / \mathrm{M}$ ratio whereas hysteresis loops at relative pressure $\mathrm{P} / \mathrm{P}_{0}$ between $0.2-1.0$ indicates the presence of meso-porosity in the samples [34].

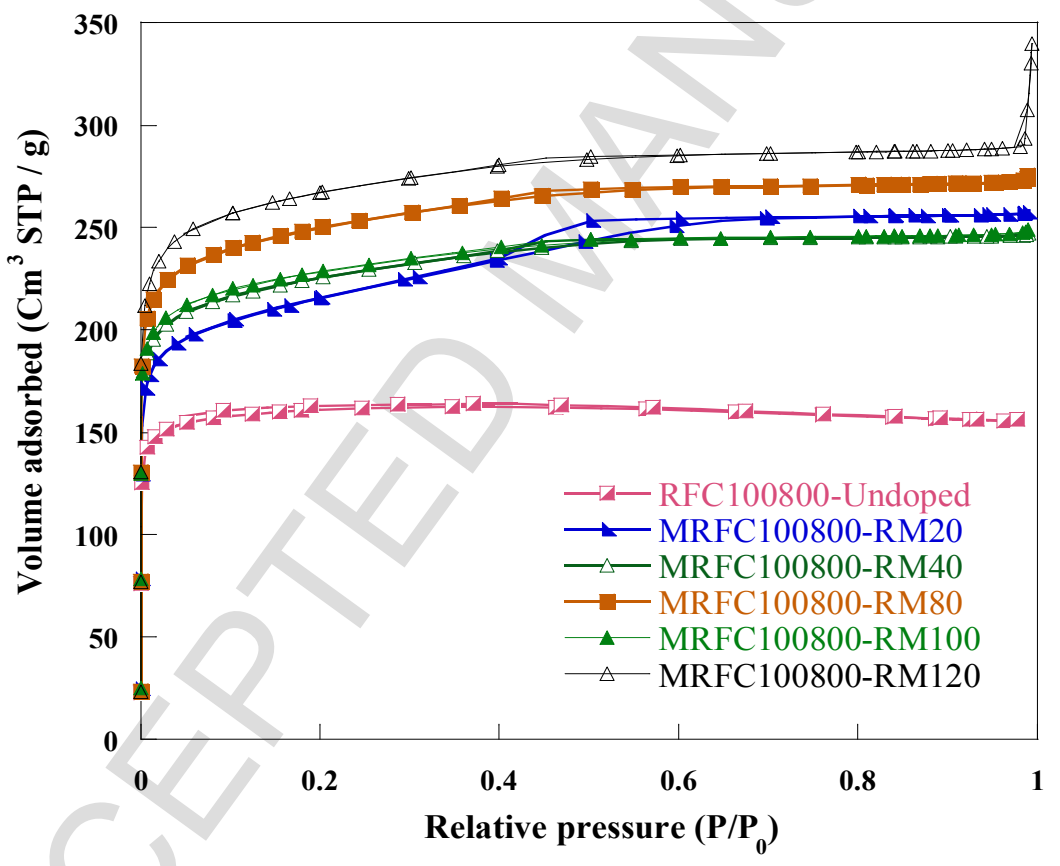

Figure 2: $\mathrm{N}_{2}$ adsorption/desorption isotherms of un-doped and nitrogen doped carbon aerogels (with different $\mathrm{R} / \mathrm{M}$ ratios) carbonized at $800{ }^{\circ} \mathrm{C}$. 


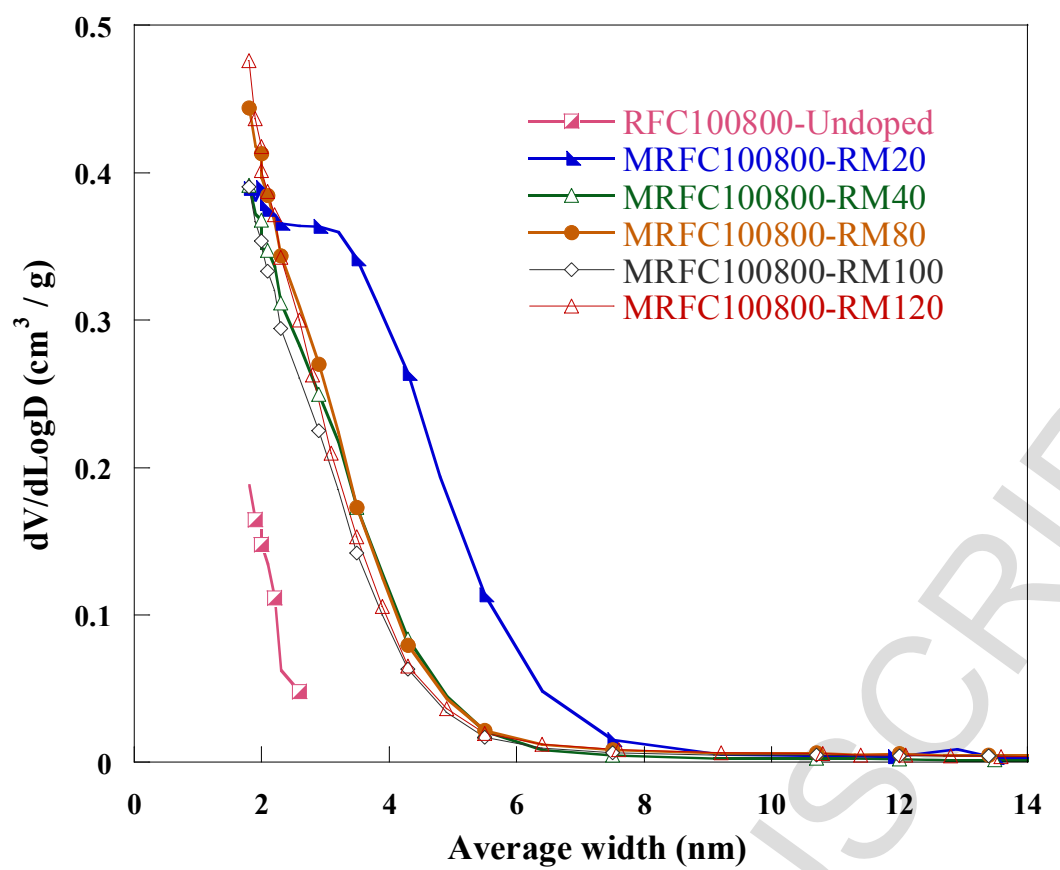

Figure 3: Pore size distribution of un-doped and nitrogen doped carbon aerogels (with different $\mathrm{R} / \mathrm{M}$ ratios) carbonized at $800{ }^{\circ} \mathrm{C}$.

Pore size distribution (PSD) of all samples presented in Figure 3 shows that they are predominantly microporous in nature with a pore size distribution centred around $2 \mathrm{~nm}$ however there is slight increase in the average pore size of the carbon with nitrogen doping as shown in Table 1.

Table 1: Porosity parameters of un-doped and nitrogen doped carbon aerogels (with different $\mathrm{R} / \mathrm{M}$ ratios) carbonized at $800^{\circ} \mathrm{C}$.

\begin{tabular}{lccccccc}
\hline Sample & $\begin{array}{c}\mathrm{S}_{\mathrm{BET}} \\
\left(\mathrm{m}^{2} \mathrm{~g}^{-1}\right)\end{array}$ & $\begin{array}{c}\mathrm{V}_{\text {total }} \\
\left(\mathrm{cm}^{3} \mathrm{~g}^{-1}\right)\end{array}$ & $\begin{array}{c}\mathrm{V}_{\text {micro }} \\
\left(\mathrm{cm}^{3} \mathrm{~g}^{-1}\right)\end{array}$ & $\begin{array}{c}\mathrm{V}_{\text {meso }} \\
\left(\mathrm{cm}^{3} \mathrm{~g}^{-1}\right)\end{array}$ & $\begin{array}{c}\mathrm{V}_{\text {micro }} \\
\%\end{array}$ & $\begin{array}{c}\mathrm{V}_{\text {meso }} \\
\%\end{array}$ & $\begin{array}{c}\mathrm{D}_{\text {ave }} \\
(\mathrm{nm})\end{array}$ \\
\hline RFC100800-un-doped & 537 & 0.242 & 0.217 & 0.025 & 90 & 10 & 1.80 \\
MRFC100800- RM20 & 723 & 0.400 & 0.221 & 0.179 & 55 & 45 & 2.21 \\
MRFC100800- RM40 & 744 & 0.385 & 0.255 & 0.129 & 66 & 34 & 2.07 \\
MRFC100800- RM80 & 841 & 0.430 & 0.283 & 0.147 & 66 & 34 & 2.05 \\
MRFC100800- RM100 & 762 & 0.388 & 0.263 & 0.125 & 68 & 32 & 2.04 \\
MRFC100800- RM120 & 900 & 0.526 & 0.307 & 0.219 & 58 & 42 & 2.34 \\
\hline
\end{tabular}

As seen, all carbons clearly possess microporous structure with similar average pore sizes. The average pore size of $\mathrm{N}$-doped carbons is slightly bigger than that of the un-doped carbon. This is most likely due to the diffusion of the nitrogen functional groups into deeper pores [35]. In can be seen that nitrogen doping increases micro-porosity in carbon with increase in 
micro-pore volume from a micro-pore volume of $0.217 \mathrm{~cm}^{3} / \mathrm{g}$ for un-doped carbon to a micro-pore volume of $0.307 \mathrm{~cm}^{3} / \mathrm{g}$ for the carbon doped with nitrogen at an R/M ratio of 120 . This might be due to the introduction of additional gelation nuclei in the gel solution upon the addition of melamine at a low concentration. The micro-pore volume of the nitrogen doped carbons then decreases with decreasing the $\mathrm{R} / \mathrm{M}$ ratio ( i.e. higher nitrogen doping) and reaches to a value of $0.221 \mathrm{~cm}^{3} / \mathrm{g}$ for the carbon doped at an $\mathrm{R} / \mathrm{M}$ ratio of 20 . This might be due to blockage of some micro-pores by nitrogen related functional groups in gel precursors synthesized at higher nitrogen contents and also could be explained that some entrances of pores are blocked by nitrogen function groups originated by the bulky melamine resins formed as a result of the heat treatment during the gelation process when producing MRF gel precursors [35]. This results in decrease in the volume of micropores and consequently decrease in the surface area of nitrogen doped carbons with increasing the nitrogen content of the carbon at lower $\mathrm{R} / \mathrm{M}$ ratios.

\subsubsection{X-Ray photoelectron spectroscopy (XPS) analysis of un-doped and nitrogen doped} ( $R / M$ ratio of 80$)$ carbon aerogels.

Table 2 summarises the elemental composition of un-doped and nitrogen doped (R/M ratio 80) carbons obtained by XPS measurements of C, O and $\mathrm{N}$ elements.

Table 2: Chemical composition of un-doped and nitrogen doped carbons (with different R/M ratios) in molar \% obtained by XPS.

\begin{tabular}{lccc}
\hline & \multicolumn{3}{c}{ Composition (molar \%) } \\
\cline { 2 - 4 } Samples & Carbon & Oxygen & Nitrogen \\
\hline RFC100800-un-doped & 94.77 & 5.20 & 0.03 \\
MRFC100800-RM80 & 95.55 & 3.90 & 0.55 \\
\hline
\end{tabular}

The data given in Table 2 shows that the nitrogen doped carbon obtained by the carbonization of the nitrogen doped aerogel prepared with $\mathrm{R} / \mathrm{M}$ ratio of 80 contains 0.55 mole $\%$ nitrogen confirming the presence of nitrogen into the matrix of the carbon material successfully. This trend was observed for the nitrogen doped carbons prepared with different R/M ratios and is in agreement with the data presented in other references [36, 37]. 


\subsubsection{Contact angle measurements of un-doped and nitrogen doped carbon aerogels}

The wettability of electrodes fabricated by using carbon aerogel (RFC100800) and nitrogen doped carbon aerogels (MRFC100800-x) with different $\mathrm{R} / \mathrm{M}$ ratios as electroactive materials was investigated when in contact with $6 \mathrm{M} \mathrm{KOH}$ solution and the values of measured contact angles are presented in Table 3.

Table 3: Contact angles for un-doped and nitrogen doped carbon aerogels (with different $\mathrm{R} / \mathrm{M}$ ratios) in contact with $6 \mathrm{M} \mathrm{KOH}$ solution.

\begin{tabular}{|c|c|}
\hline Samples & Contact angle $(\theta)$ (Degree) \\
\hline RFC100800-un-doped & 123 \\
\hline MRFC100800-RM60 & \\
\hline MRFC100800-RM80 & \\
\hline MRFC100800-RM100 & 109 \\
\hline MRFC100800-RM120 & 106 \\
\hline
\end{tabular}

The values of contact angles given in Table 3 show a considerable improvement in wetting behaviour of the carbons with a decrease in contact angle from $123^{\circ}$ to the value of $103^{\circ}$ after nitrogen doping. Since all the samples have similar porous structure, a drastic drop in contact angle of the samples can be attributed to the change in their surface chemistry with the introduction of nitrogen functional groups [36]. The lowest contact angle of $103^{\circ}$ is observed for the nitrogen doped carbon with $\mathrm{R} / \mathrm{M}$ ratio of 80 , although the entire sample range still shows contact angles above $90^{\circ}$ and remains somehow hydrophobic. It has been shown that compared with common non-polar carbons, N-containing carbons are incorporated with more heterogeneous polar species and show better wettability $[38,39]$. These polar nitrogen groups as hydrophilic species improve the surface affinity toward aqueous $\mathrm{KOH}$ solution having the same polarity, and favor the wetting of electrode and then the ion transportation. Nitrogen contains five valence electrons available to bond with carbon atoms and induces negative doping on carbon. Therefore nitrogen doping especially into the carbon network improves its charge transfers and activities. Li et al. [40] have shown that nitrogen doping and subsequently the substitution of some carbon atoms with nitrogen atoms in the material's network, which introduces the unpaired electron, will change the atomic charge distribution by introducing defects and disorder in carbon surface increasing wettability between electrode and electrolyte. This will enhance the capacitive performance of the electrode as seen in the results of electrochemical measurements given below. 


\subsubsection{SEM analysis of un-doped and nitrogen doped carbon aerogels}

The microstructure of un-doped and nitrogen doped carbon aerogel samples is characterized by scanning electron microscopy. The SEM images of the samples at various magnifications are shown in Figure 4.
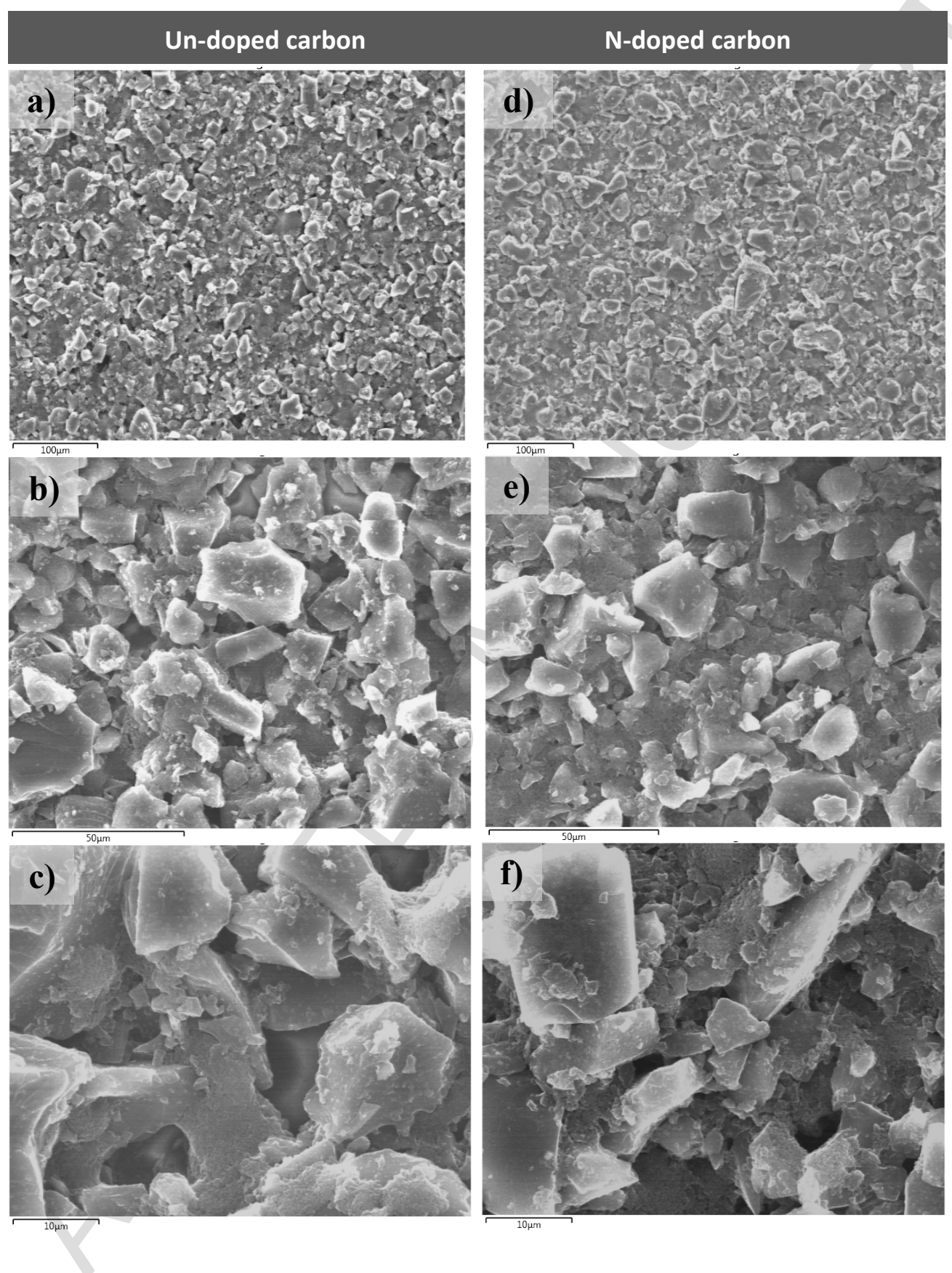

Figure 4: a, b, c) SEM images of un-doped carbon (RFC100800-un-doped), d, e, f) SEM images of N- doped carbon (MRFC100800 -RM80) at magnifications of 100, 50 and $10 \mu \mathrm{m}$.

As seen both un-doped and nitrogen doped carbon aerogel samples display bulk structure with irregular particle morphology including highly porous surface (as analysed by BET) 
with similar morphological structure. There is no significant change in overall structure of carbon aerogel samples after nitrogen doping. However the nitrogen doped sample shows a denser structure with filled inter-particle spaces as compared to the more open structure of the un-doped sample. This is mainly due to the formation of smaller particles resulting in more compact structure through the introduction of additional gelation sites with introducing melamine to the gel solution. This will in turn results in diffusion of nitrogen into deeper pores at nano-scale resulting in decrease in micro-porosity and surface area of N-doped carbons with higher nitrogen doping at lower R/M ratios as observed by BET results above.

\subsubsection{XRD Analysis of un-doped and nitrogen doped carbon aerogels}

The phase structure of un-doped and nitrogen doped carbon samples was characterized by XRD and the results are shown in Figure 5 where two broad and low-intensity diffraction peaks at $2 \theta$ around $23^{\circ}$ and $44^{\circ}$ were observed for both un-doped and nitrogen doped carbon samples which are typically observed in carbons [41, 42]. The pick positions shown on XRD spectra in Figure 5 are indexed to (002) and (100) spacing which are indication of disordered (amorphous) structure for carbons aerogels [42, 43]. However, the low intensity and broadness of the two peaks indicates a low degree of graphitization for the produced carbons. Decrease in the intensity of the peaks for MRFC100800-RM80 carbon is mainly due to a highly disordered structure as a result of introducing defects and disorder by nitrogen doping.

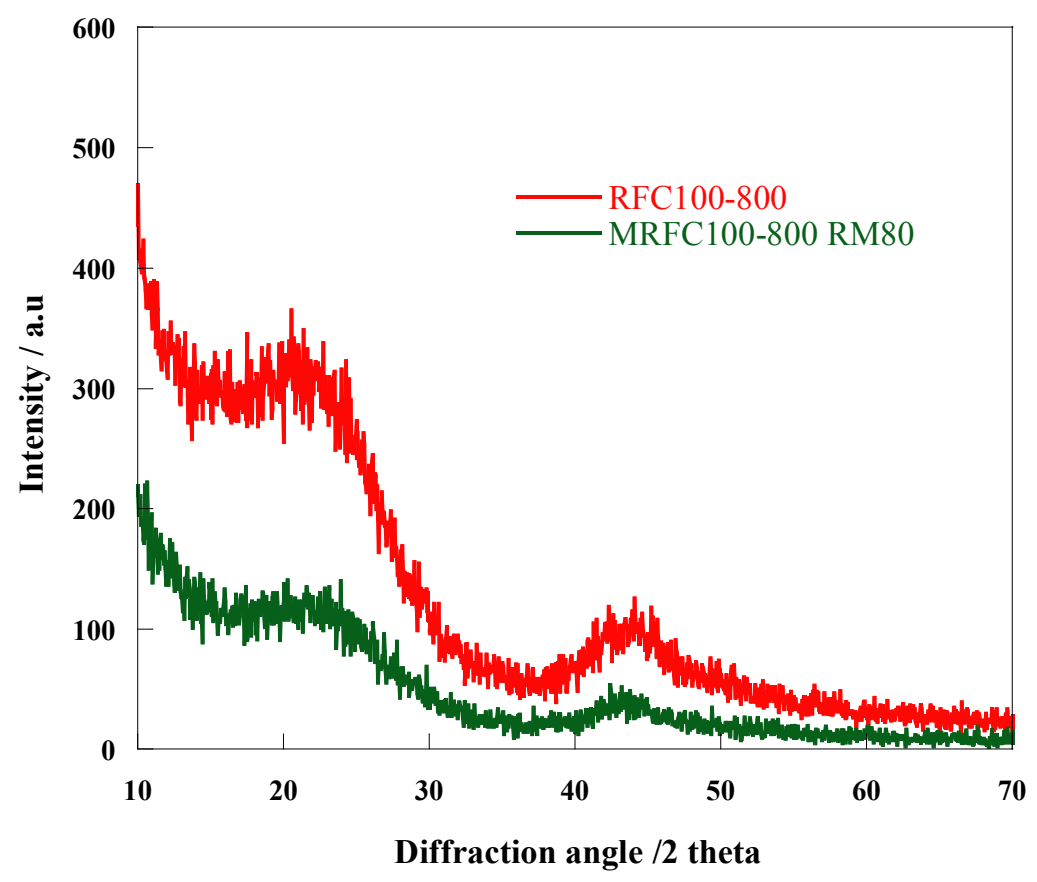

Figure 5: Typical XRD spectra of un-doped (RFC100800 un-doped) and nitrogen doped (MRFC100800-RM80) carbon aerogel samples. 


\subsection{Electrochemical characterization}

Figure 6 shows cyclic voltammograms of MRFC100800-RM80 sample used as electroactive material with $6 \mathrm{M} \mathrm{KOH}$ electrolyte in an EC cell measured at different scan rates.

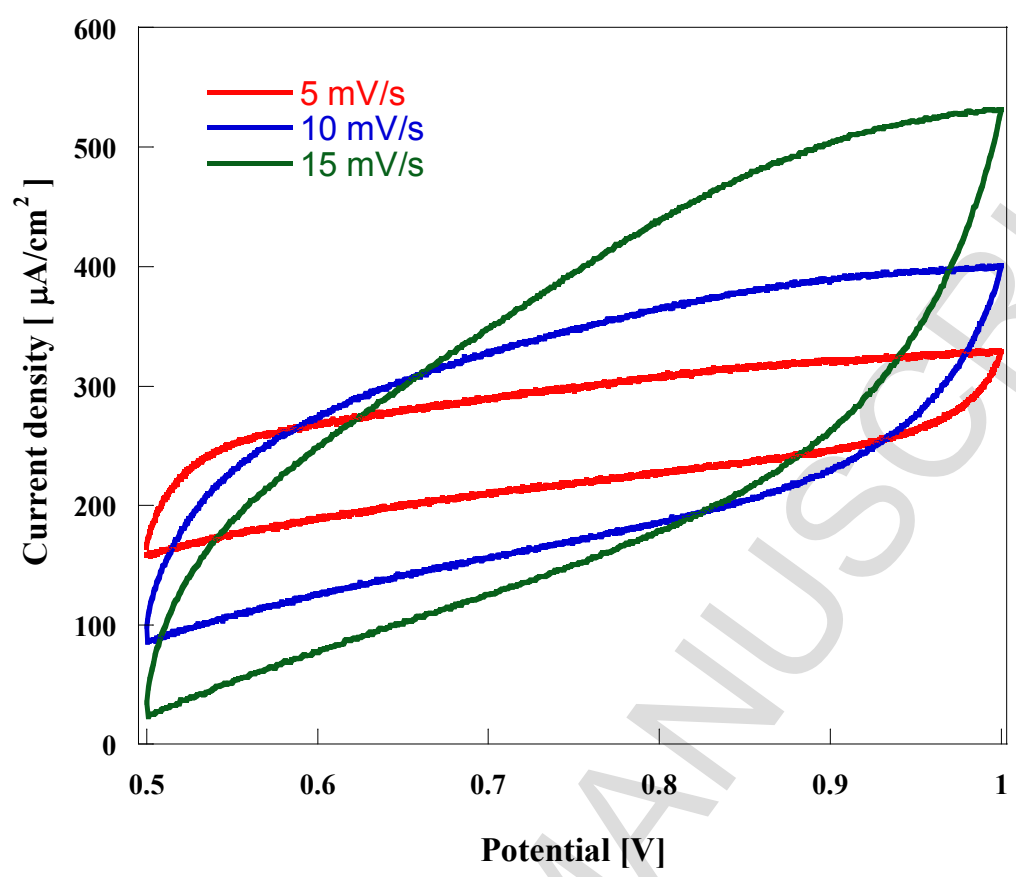

Figure 6: Cyclic voltammogram of the cell using MRFC100800-RM80 carbon aerogel as electroactive material at different scan rates.

The CV curves are nearly rectangular and symmetric in shape especially at a low scan rate of $5 \mathrm{mVs}^{-1}$ which is an indication of good capacitive behaviour. The deviation of CV curves from the perfect rectangular shape at higher scan rates is due to several phenomena including i) the solution/charge transfer resistances of the electrolyte ii) the contact resistance between the electrode and the current collector, and iii) diffusional and kinetic limitations [44].

The CV loops are gradually depressed and became distorted as the scan rate increases. This can be attributed to the kinetic effects and poor ion diffusion at higher scan rates where narrow pores hinder the accessibility of the electrolyte to the internal surface area of active material at higher scan rates [45].

Table 4 shows the specific capacitance of un-doped carbon aerogel and nitrogen doped carbon aerogels with different $\mathrm{R} / \mathrm{M}$ ratios used as the electroactive material with $6 \mathrm{M} \mathrm{KOH}$ in an EC cell measured at different scan rates. 
Table 4: Specific capacitance of the EC cell at different scan rates using nu-doped and nitrogen doped carbon aerogels as the electroactive material.

\begin{tabular}{lcrcr}
\hline & & \multicolumn{3}{c}{ Specific capacitance $\left(\mathrm{Fg}^{-1}\right)$} \\
Sample & $\mathrm{S}_{\mathrm{BET}}\left(\mathrm{m}^{2} \mathrm{~g}^{-1}\right)$ & \multicolumn{2}{c}{ Scan rate $\left(\mathrm{mVs}^{-1}\right)$} & 10 \\
\cline { 3 - 5 } & & 5 & 71 & 51 \\
\hline MRFC100800-un-doped & 537 & 29 & 13 & 8 \\
MRFC100800-RM 20 & 723 & 79 & 19 & 11 \\
MRFC100800-RM 40 & 744 & 208 & 70 & 19 \\
MRFC100800-RM 80 & 841 & 198 & 63 & 32 \\
MRFC100800-RM 100 & 761 & 141 & 42 & 29 \\
MRFC100800-RM 120 & 900 & &
\end{tabular}

As seen, the introduction of nitrogen in the bulk of the carbon used as the electroactive material improves the capacitive performance of the electrochemical capacitor cell with the highest specific capacitance obtained for the nitrogen doped carbon aerogel with an $\mathrm{R} / \mathrm{M}$ ratio of 80. This can be due to the improvements in physical properties of carbon material, including its conductivity, wettability, and pseudocapacitive charge storage ability induced by doping of nitrogen combined with its double layer capacitive charge storage ability because of its high surface area $[39,46,47]$.

Data given in Table 4 shows that all carbons exhibit their highest capacitance at a scan rate of $5 \mathrm{mVs}^{-1}$ and by increasing the scan rate a significant drop in the specific capacitance of all carbons is observed which is probably due to the inaccessibility of inner active surface area of the electrode to electrolyte due to fast potential changes [48]. Since there is no significant change in porous parameters of the active material after nitrogen doping as presented in Table 1 , the observed improvement in the capacitance with nitrogen content in the R/M range of 120 to 80 is presumably due to the pseudo-capacitive contributions of the introduced nitrogen heteroatoms within the sample skeleton. Nitrogen has electron donner characteristics which results in pseudo capacitance [49]. In this case the total capacitance of the cell is the sum of both pseudo capacitance and electric double layer capacitance where pseudo-capacitive contribution is made by the nitrogen doping and electric double layer capacitance is due to the formation of electric double layer at electrode/ electrolyte interface.

As discussed above and shown in Table 1, nitrogen doping does not change the pore size of carbons significantly (around $2 \mathrm{~nm}$ ), although it increases the specific surface area with the 
highest value of $900 \mathrm{~m}^{2} \mathrm{~g}^{-1}$ achieved for the carbon with an $\mathrm{R} / \mathrm{M}=120$. The texture is one main factor that affects the capacitive performance of carbon materials, where the $\mathrm{N}$ dopants are another that alters their properties. A high capacitance would prefer both surface area and $\mathrm{N}$-doping to be as high as possible, however in reality the trends of the surface area and the level of N-doping in carbon are in opposite directions due to the synthetic limitations and turn out trade-off between each other. It has been discussed that enlarging the effective surface area in nitrogen doped carbons is accompanied by decrease in their N-content owing to the decomposition of functional species [50-53]. This opposite trend has been shown in Table 1 by decrease in the surface area of $\mathrm{N}$-doped carbons from $900 \mathrm{~m}^{2} \mathrm{~g}^{-1}$ to $723 \mathrm{~m}^{2} \mathrm{~g}^{-1}$ when increasing the nitrogen content of carbon by changing its R/M ratio in the range of 120 to 20 . In the case of carbon with $\mathrm{R} / \mathrm{M}=120$, although the surface area is in its maximum value and EDLCs are enhanced by enlarging the specific surface area, however pseudo-capacitance will be significantly impaired and the material shows a low specific capacitance of $141 \mathrm{Fg}^{-1}$. For the carbon with $\mathrm{R} / \mathrm{M}=20$, the surface area is decreased, and N-doping is in its highest level, however the material even shows a much lower specific capacitance of $29 \mathrm{Fg}^{-1}$. Yang and Zhuo [54] have reported that a certain amount of electron-donor $\mathrm{N}$ dopants along with induced structural defects/voids offer excellent electrical conductivity and transport paths, resulting in highly efficient electron and ion transfers. They have discussed that although the introduction of $\mathrm{N}$ heteroatoms enhances the electron donor characteristics of carbon layers and provides abundant electrochemically active sites for pseudocapacitive reactions, however the limited $\mathrm{N}$ doping level usually hinders the exertion of positive effects, which only stops at increasing conductivity. As a result of this super-capacitive performance usually shows the non-linear correlation with the $\mathrm{N}$ content with an optimum capacitance, which could be also found in other reports on the capacitive behavior of $\mathrm{N}$ - doped porous carbons [50, 55-58].

Figure 7 shows the variation of specific capacitance of the EC cell with R/M ratio of carbons used as electroactive material obtained at different scan rates. It can be seen that the carbon with $\mathrm{R} / \mathrm{M}$ ratio of 80 gives the highest specific capacitance among all samples with the maximum specific capacitance of $208 \mathrm{Fg}^{-1}$ obtained at a scan rate of $5 \mathrm{mVs}^{-1}$ indicating an $\mathrm{R} / \mathrm{M}$ ratio of 80 results in the best performance for the combined capacitive performance of the carbon at low scan rates. 


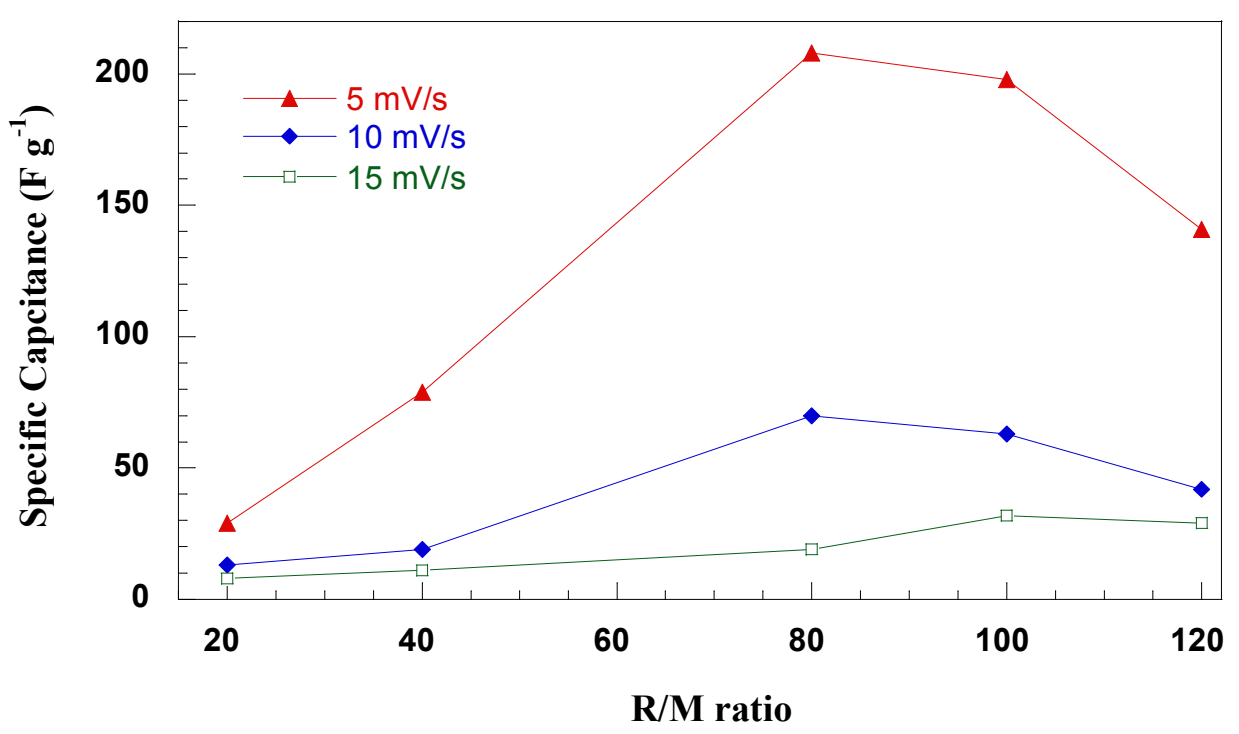

Figure 7: Variations in specific capacitance of the $\mathrm{EC}$ cell with the $\mathrm{R} / \mathrm{M}$ ratio of nitrogen doped carbons used as electroactive material at different scan rates.

Significant increase in the specific capacitance of the sample with RM80 particularly in lower scan rates clearly indicates its improved capacitance due to the combined pseudo-capacitive effect originated from nitrogen doping at an optimum level and electric double layer capacitive effect originated from the carbon's surface area.

A decline in specific capacitance is observed when $\mathrm{R} / \mathrm{M}$ ratio increases beyond the $\mathrm{R} / \mathrm{M}$ ratio of $80(80<\mathrm{R} / \mathrm{M} \leq 120)$. Ismagilov et al.[59] have discussed that substitutional introduction of more electron-rich nitrogen into the carbon network could bring more electrons to the delocalized $\pi$-system of carbon materials, which leads to increased electrical conductivity of the network. They have shown that the dependence of the conductivity on the nitrogen content is non-monotone and the maximum conductivity happens at the intermediate nitrogen concentrations. It has also been shown that the configuration with nitrogen substituting for carbon atoms without destroying their sp2 network is beneficial to improve the electrical conductivity [14]. There is an optimum nitrogen concentration $(\mathrm{R} / \mathrm{M}=80)$ at which the effect of doping and introduction of nitrogen species grants the electron donor characteristics of carbon layers and provides abundant electrochemically active sites for pseudocapacitive reactions. In this case nitrogen doping results in the injection of extra electrons and leads to the increase of density of states at the Fermi level, thus enhancing the capacitance of carbon near the Fermi level when compared with the capacitance of un-doped carbon. This is also proved by the study of the effect of nitrogen concentration on capacitance, density of states, electronic conductivity, and morphology of N-doped carbon nanotube electrodes [60]. 
Nitrogen doping at higher nitrogen concentrations beyond this level (i.e., $\mathrm{R} / \mathrm{M}<80$ ) decreases the current carriers mobility in the carbon sample and hinders the exertion of positive effects $[14,54]$. In a study of the effect of doping on the density-of-states (DOS) distribution and charge-carrier transport in a disordered hopping system, Arkhipov et al. [61] have shown that doping produces a random distribution of dopant ions, which Coulombically interact with carriers localized in intrinsic hopping sites. This interaction further increases the energy disorder and broadens the deep tail of the DOS distribution. Therefore, doping of disordered carbons with nitrogen at higher concentrations, on the one hand, increases the concentration of charge carriers and lifts up the Fermi level but, on the other hand, creates additional deep Coulombic traps of the opposite polarity. While the former effect facilitates conductivity of the carbon sample, the latter strongly suppresses the carrier hopping rate with increasing N-doping levels. In a study of the electrical conductivity of nitride carbon films with different nitrogen content, Zhang et al. [62] have also shown that the electrical conductivity of the deposited films increases slowly with increasing nitrogen content, and then decreases after the nitrogen content in the film reaches a certain value of 12.8 atomic $\%$. They have explained that for the films with low nitrogen content, the valence electrons of nitrogen as the impurity centre can be saturated easily by $\mathrm{H}$ where the doping effect is not obvious. After suitable annealing, the $\mathrm{N}-\mathrm{H}$ bond can be decomposed, which activates the impurity centre, then the electrical conductivity increases. In the case of heavily doped films where the nitrogen content in the films is high, annealing at higher temperatures has a little effect and the film appear to be a nonconductive carbon nitride. This might be the case for nitrogen doped carbons prepared from MRF gels doped with nitrogen at different $\mathrm{R} / \mathrm{M}$ ratios in this work where the conductivity of lightly loaded carbon aerogels prepared at R/M ratio in the range of 80 to 120 , increases with increasing their nitrogen content (or decreasing R/M ratio) due to increase in active nitrogen centres created within the carbon structure after carbonization and reaches to a maximum at $\mathrm{R} / \mathrm{M}=80$. Increasing the nitrogen content of the carbon beyond the nitrogen content at an R/M ratio of 80 by decreasing $\mathrm{R} / \mathrm{M}$ ratio below 80 , will saturate the carbon network with nitrogen, create additional deep Coulombic traps in the carbon structure and increase the opposite polarity in the electrode. This results in decrease in the hopping rate of nitrogen active sites within the carbon structure and as a whole decreases the electrochemical performance of nitrogen doped carbon with increasing N-doping levels.

Figure 8 shows the Nyquist plot obtained for the EC cell using the un-doped carbon and nitrogen doped carbons with different $\mathrm{R} / \mathrm{M}$ ratios as electroactive material in the frequency 
range of $100 \mathrm{KHz}$ to $50 \mathrm{~Hz}$. Semi-straight line in lower frequency region corresponds to near ideal capacitive behaviour followed by a semicircle not separated clearly at higher frequency region. This might be due to the enhanced conductivity of nitrogen doped electrode material [63]. It can be seen from the inset that the curve representing sample MRFCA100800-RM80 originates at very low value of resistance on the real axis $\left(\mathrm{Zr}^{\prime}\right)$. This is an indication of low equivalent series resistance for the EC cell using this sample as the electroactive material. These results show an improved electron transfer for the carbon and it is in line with the results of contact angle measurements (the lowest contact angle value) for this sample. On the other hand, the introduction of $\mathrm{N}$ species in an optimum level endows the electron donor characteristics of carbon layers and provides abundant electrochemically active sites within the electroactive material for pseudocapacitive reactions with improved conductivity[15].

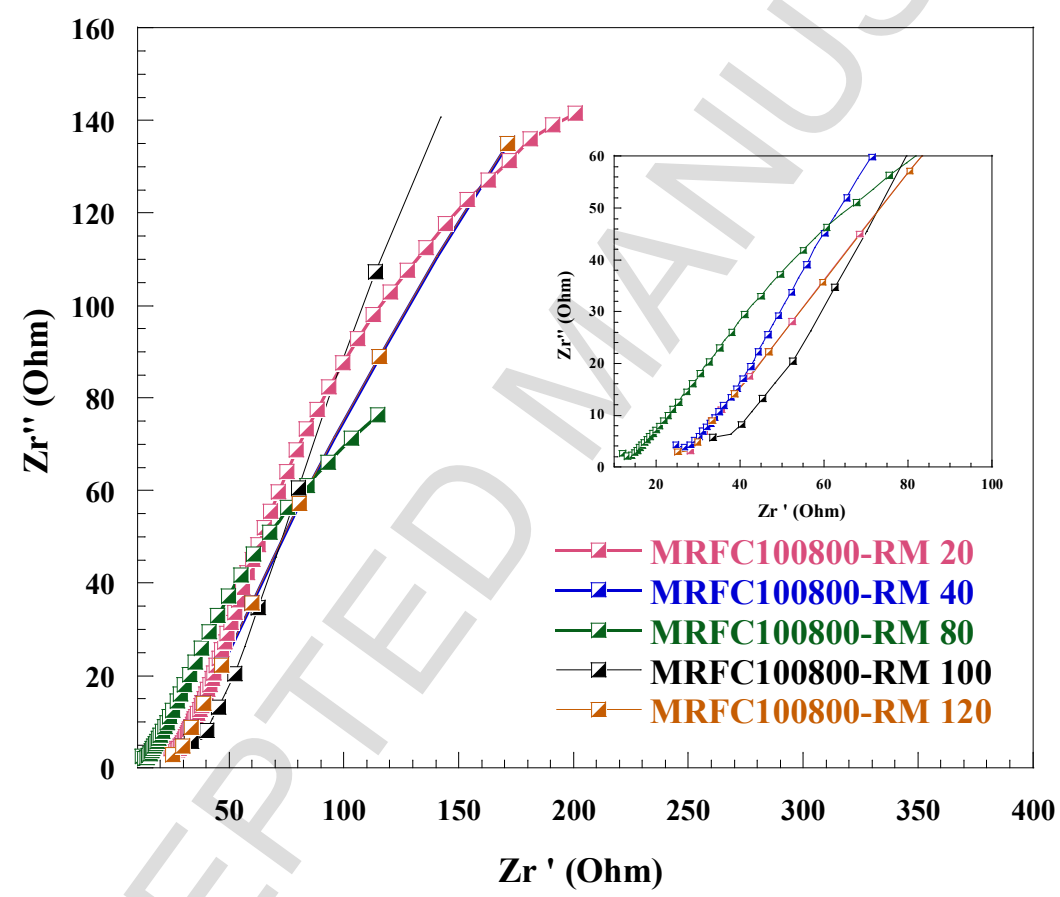

Figure 8: EIS spectra of nitrogen doped carbon aerogels with different R/M ratios used as the electroactive material with $6 \mathrm{M} \mathrm{KOH}$ electrolyte in the EC cell.

The experimental data obtained from EIS experiments indicates that electrode and electrolyte are related by a mixed kinetic and diffusion processes at the electrode surface causing polarization at the electrode/electrolyte interface. The EIS data was fitted to the equivalent circuit shown as inset in Figure 9 in which $R_{s}$ represents solution resistance and can be calculated by high frequency intercept of EIS spectrum on the real axis, CPE is the constant phase element accounting for non-ideal behaviour of the double layer capacitor and the polarisation resistance $R_{p}$ signifies the barrier between the catholic and anodic current flow 
throughout the cell. The polarisation resistance includes the charge transfer resistance $R_{c t}$ determined by the diameter of medium range semicircle, and diffusion resistance or Warburg effect $Z_{\mathrm{W}}$ at high frequency range of the EIS spectrum. The results of measured and calculated impedance data for MRFC100800-RM80 carbon sample are shown in Figure 9 where experimental curve is in a good agreement with the fitted curve calculated by using the equivalent circuit given as inset in Figure 9.

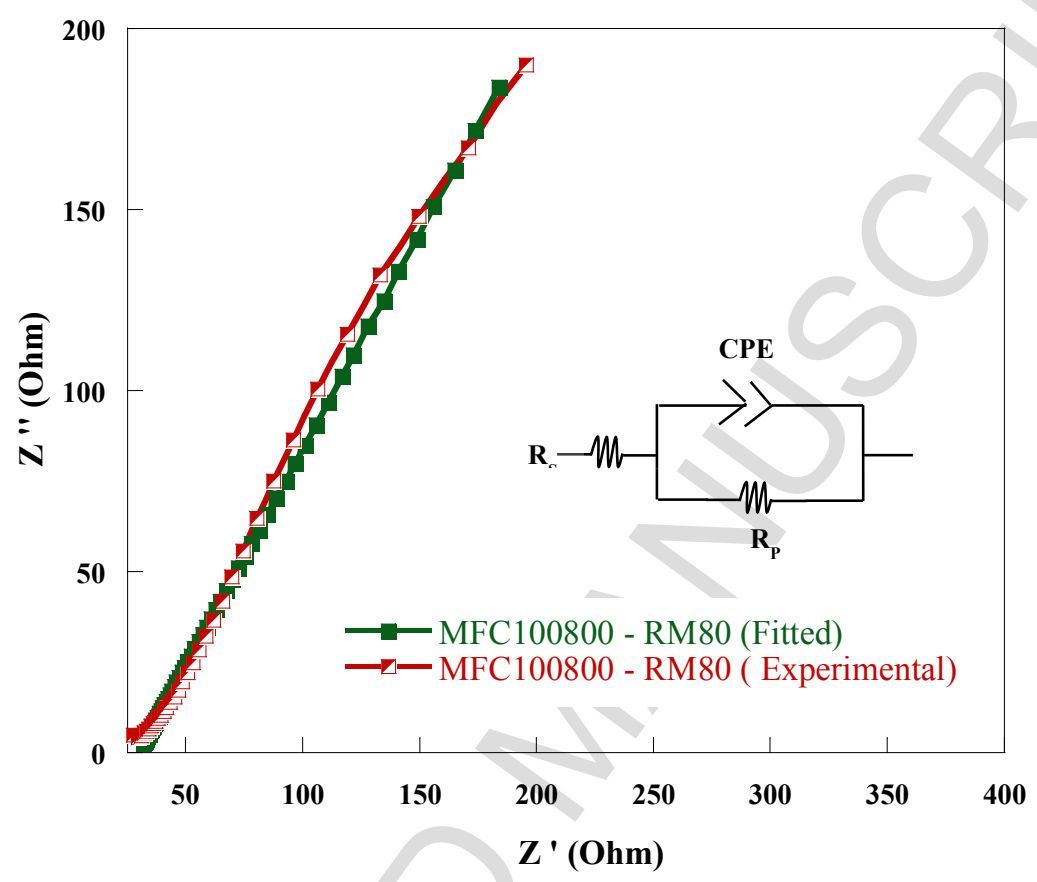

Figure 9: Measured and calculated EIS spectra of MRFC100800-RM80 carbon sample using the equivalent circuit given as insert.

Table 5 represents the solution resistance $\left(R_{S}\right)$ and the charge transfer resistance $\left(R_{C T}\right)$ determined by fitting the EIS experimental data to the equivalent circuit for un-doped sample and also nitrogen doped carbon sample MRFC100800-RM80 with the highest specific capacitance and lowest electrode/electrolyte contact angle, used as electroactive materials in the electrode formulation when in contact with $6 \mathrm{M} \mathrm{KOH}$ solution in EC cell.

Table 5 Dependence of the equivalent-circuit parameters upon the type of carbon sample (un-doped/N-doped) used in the electrode formulation.

\begin{tabular}{ccc}
\hline Sample & $\begin{array}{c}\text { Solution Resistance } \\
\mathrm{R}_{\mathrm{S}}(\Omega)\end{array}$ & $\begin{array}{c}\text { Charge Transfer Resistance } \\
\mathrm{R}_{\mathrm{CT}}(\Omega)\end{array}$ \\
\hline RFC100800 & 0.57 & 0.05 \\
MRFC100800-RM80 & 0.15 & 0.04 \\
\hline
\end{tabular}


Both types of resistances vary with the change in sample type. Nitrogen doped sample with $\mathrm{R} / \mathrm{M}$ ratio of 80 has seen decline in both solution and charge transfer resistance when compared with those of un-doped sample as given in Table 5. This might be related to faster ion diffusion due to improved wettability and conductivity of the carbons after the introduction of nitrogen functional groups $[11,30]$ with nitrogen doping. Substantial decrease in the solution resistance $\mathrm{R}_{\mathrm{s}}$ for MRFC100800-RM80 sample is mainly attributed to the good electrode/electrolyte contact of the sample as witnessed by the contact angle measurements. Tiny semicircle for the sample pronounced at high frequency region indicates low resistance to charge transfer for the sample due to its improved conductivity with N-doping.

\section{Conclusions}

High porosity polymeric carbon aerogels (un-doped/nitrogen doped) have been synthesized through polycondensation of resorcinol with formaldehyde using melamine as nitrogen source to prepare RF aerogel and nitrogen doped MRF aerogels with different level of nitrogen contents followed by their carbonization at $800{ }^{\circ} \mathrm{C}$ under inert environment in constant flow of Ar.

BET analysis of the carbon samples showed that all samples are microporous with average pore size of around $2 \mathrm{~nm}$ and no substantial change in their average pore size with nitrogen doping. Micro-pore volume and surface area of the carbon increased significantly with the introduction of nitrogen at a low concentration $(\mathrm{R} / \mathrm{M}=120)$ mainly due to the introduction of additional gelation nuclei in the gel solution and they then decreased with increasing nitrogen doping (i.e. decreasing the $\mathrm{R} / \mathrm{M}$ ratio) probably due to the blockage of micro-pores by nitrogen related functional groups and formation of bulky melamine resins at the entrance of pores in gel precursors. The results of XRD analysis showed that all samples have amorphous structure, retaining low degree of graphitization and doping carbon with nitrogen results in more defects and disorder in its structure. X-Ray photoelectron spectroscopy (XPS) analysis confirmed the incorporation of nitrogen into the carbon matrix with a nitrogen content of 0.55 mole $\%$ for $\mathrm{N}$-doped carbon prepared with an $\mathrm{R} / \mathrm{M}$ ratio of 80 . Contact angle measurements of the electrodes made from un-doped/nitrogen doped carbons in contact with $6 \mathrm{M} \mathrm{KOH}$ solution showed that nitrogen doping and subsequently the substitution of some carbon atoms with nitrogen atoms increases wettability between electrode and electrolyte as a result of change in the atomic charge distribution by introducing unpaired electrons in the material's network and defects and disorder in carbon surface. SEM micrograms of nitrogen doped carbon also 
showed a denser structure with filled inter-particle spaces as compared to the more open structure of un-doped carbon.

The results of electrochemical measurements revealed that the introduction of nitrogen in the bulk of the carbon improves the capacitive performance of electrochemical capacitor cell when decreasing $\mathrm{R} / \mathrm{M}$ in the range of 120 80. This is mainly associated with the double layer capacitive charge storage ability of the carbon because of its high surface combined with: i) increase in the conductivity of the electrode since substitutional addition of more electronrich nitrogen atoms into the network of carbon exerts more electrons to carbon's delocalized $\pi$-system leading to its increased electrical conductivity ii) the pseudo capacitive contribution of nitrogen function groups introduced into the bulk carbon, since nitrogen doping provides abundant electrochemically active sites for pseudocapacitive reactions, and ii) improvement in wetting behaviour of the electrode in contact with electrolyte, since nitrogen doping improves the surface chemistry of carbon by introducing more heterogeneous species and unpaired electrons and changing the atomic charge distribution on its surface. However the dependence of the specific capacitance of the cell on the nitrogen content of carbon is nonlinear and an $\mathrm{R} / \mathrm{M}$ ratio of 80 (i.e. nitrogen content of $0.55 \mathrm{~mol} \%$ ) is the optimum $\mathrm{R} / \mathrm{M}$ ratio at which nitrogen doping results in superior performance of the cell. Doping of the carbon with nitrogen at higher concentrations (i.e. $\mathrm{R} / \mathrm{M}<80$ ) suppresses the carrier hopping rate of dopant and results in significant decrease in the specific capacitance and electrochemical performance of the cell.

The EIS spectra of un-doped/nitrogen doped carbons also showed that, nitrogen doping at an optimum level $(\mathrm{R} / \mathrm{M}=80)$ decreases the impedance of porous carbon electrode due to improved diffusivity/ion transfer and reduces charge transfer and contact resistances of electrolyte when in contact with porous media of active material.

Recommendations: Due to their fast charge/discharge responses and long cycle lives; supercapacitors are considered as the key complementary device to support batteries and other electrochemical storage/conversion devices in any energy storage/delivery system, enabling higher system peak power performance. Despite an intensive research and numerous published works on electrode and electrolyte materials to improve their performance when used for different applications and particularly to promote their energy density towards battery-level energy density, there are a number of features of their electrode materials that remain unclear and moreover many aspects of functioning of these materials in the device are 
not fully understood yet. The results of this study demonstrates that nitrogen doping can be used as a suitable method to favourably tune the physiochemical properties and the electrochemical performance of carbon based electrodes through simultaneous improvement in their porous structure, wettability, electrical conductivity, and introduction of addition of extra electrochemically-active sites which in turn results in introducing pseudo-capacitive element to the device as a result of redox reactions at/near carbon surface at an optimum nitrogen content. In this respect, further research on doping type, contents and moreover on co-doping through the incorporation of other dopants such as sulphur and phosphorus to balance porosity/wettability/ conductivity/active sites of the carbon based electrodes for the optimal electrochemical performance of the device based on specific requirements of particular applications is required. In addition, since the electrochemical window of the electrolyte is an important parameter in promoting the energy density of supercapacitors, the trade-off among dopant-content, porous structure, wettability and electrical conductivity of the electrode when in contact with organic/ionic liquid electrolytes with wider electrochemical windows will have definite impact on the electrochemical performance of the device and such investigations are needed for the development of supercapacitors with high power/energy densities to fulfil our future energy demands.

\section{References}

[1] J. Theerthagiri, G. Durai, K. Karuppasamy, P. Arunachalam, V. Elakkiya, P. Kuppusami, et al., "Recent Advances in 2-D Nanostructured Metal Nitrides, Carbides, and Phosphides Electrodes for Electrochemical Supercapacitors-A Brief Review," Journal of Industrial and Engineering Chemistry, 2018.

[2] A. Allagui, T. J. Freeborn, A. S. Elwakil, M. E. Fouda, B. J. Maundy, A. G. Radwan, et al., "Review of fractional-order electrical characterization of supercapacitors," Journal of Power Sources, vol. 400, pp. 457-467, 2018.

[3] P. J. Hall, M. Mirzaeian, S. I. Fletcher, F. B. Sillars, A. J. Rennie, G. O. Shitta-Bey, et al., "Energy storage in electrochemical capacitors: designing functional materials to improve performance," Energy \& Environmental Science, vol. 3, pp. 1238-1251, 2010.

[4] M. F. Iqbal, M. N. Ashiq, M.-U. Hassan, R. Nawaz, A. Masood, and A. Razaq, "Excellent electrochemical behavior of graphene oxide based aluminum sulfide nanowalls for supercapacitor applications," Energy, 2018.

[5] J. Bao, C. Liang, H. Lu, H. Lin, Z. Shi, S. Feng, et al., "Facile fabrication of porous carbon microtube with surrounding carbon skeleton for long-life electrochemical capacitive energy storage," Energy, vol. 155, pp. 899-908, 2018.

[6] M. Mirzaeian, Q. Abbas, A. Ogwu, P. Hall, M. Goldin, M. Mirzaeian, et al., "Electrode and electrolyte materials for electrochemical capacitors," international journal of hydrogen energy, vol. 42, pp. 25565-25587, 2017.

[7] S. Zheng, Z.-S. Wu, S. Wang, H. Xiao, F. Zhou, C. Sun, et al., "Graphene-based materials for high-voltage and high-energy asymmetric supercapacitors," Energy Storage Materials, vol. 6, pp. 70-97, 2017. 
[8] A. Borenstein, O. Hanna, R. Attias, S. Luski, T. Brousse, and D. Aurbach, "Carbon-based composite materials for supercapacitor electrodes: a review," Journal of Materials Chemistry A, vol. 5, pp. 12653-12672, 2017.

[9] M. Cakici, R. R. Kakarla, and F. Alonso-Marroquin, "Advanced electrochemical energy storage supercapacitors based on the flexible carbon fiber fabric-coated with uniform coral-like MnO2 structured electrodes," Chemical Engineering Journal, vol. 309, pp. 151-158, 2017.

[10] M. Oschatz, S. Boukhalfa, W. Nickel, J. P. Hofmann, C. Fischer, G. Yushin, et al., "Carbidederived carbon aerogels with tunable pore structure as versatile electrode material in high power supercapacitors," Carbon, vol. 113, pp. 283-291, 2017.

[11] Q. Abbas, M. Mirzaeian, A. A. Ogwu, M. Mazur, and D. Gibson, "Effect of physical activation/surface functional groups on wettability and electrochemical performance of carbon/activated carbon aerogels based electrode materials for electrochemical capacitors," International Journal of Hydrogen Energy, 2018.

[12] Q. Abbas, M. Mirzaeian, and A. A. Ogwu, "Electrochemical performance of controlled porosity resorcinol/formaldehyde based carbons as electrode materials for supercapacitor applications," International Journal of Hydrogen Energy, 2017.

[13] F. B. Sillars, S. I. Fletcher, M. Mirzaeian, and P. J. Hall, "Effect of activated carbon xerogel pore size on the capacitance performance of ionic liquid electrolytes," Energy \& Environmental Science, vol. 4, pp. 695-706, 2011.

[14] D. Hulicova-Jurcakova, M. Seredych, G. Q. Lu, and T. J. Bandosz, "Combined effect of nitrogen-and oxygen-containing functional groups of microporous activated carbon on its electrochemical performance in supercapacitors," Advanced functional materials, vol. 19, pp. 438-447, 2009.

[15] M. Sevilla and R. Mokaya, "Energy storage applications of activated carbons: supercapacitors and hydrogen storage," Energy \& Environmental Science, vol. 7, pp. 1250-1280, 2014.

[16] C. Zheng, W. Qian, C. Cui, G. Xu, M. Zhao, G. Tian, et al., "Carbon nanotubes for supercapacitors: consideration of cost and chemical vapor deposition techniques," Journal of Natural Gas Chemistry, vol. 21, pp. 233-240, 2012.

[17] Y. He, W. Chen, C. Gao, J. Zhou, X. Li, and E. Xie, "An overview of carbon materials for flexible electrochemical capacitors," Nanoscale, vol. 5, pp. 8799-8820, 2013.

[18] P. B. Karandikar, D. B. Talange, U.P. Mhaskar, and R. Bansal, "Development, modeling and characterization of aqueous metal oxide based supercapacitor," Energy, vol. 40, pp. 131-138, 2012.

[19] F. Miao, C. Shao, X. Li, N. Lu, K. Wang, X. Zhang, et al., "Polyaniline-coated electrospun carbon nanofibers with high mass loading and enhanced capacitive performance as freestanding electrodes for flexible solid-state supercapacitors," Energy, vol. 95, pp. 233241, 2016.

[20] W. Wang, S. Guo, I. Lee, K. Ahmed, J. Zhong, Z. Favors, et al., "Hydrous ruthenium oxide nanoparticles anchored to graphene and carbon nanotube hybrid foam for supercapacitors," Scientific reports, vol. 4, p. 4452, 2014.

[21] A. I. Oje, A. Ogwu, M. Mirzaeian, and N. Tsendzughul, "Electrochemical energy storage of silver and silver oxide thin films in an aqueous $\mathrm{NaCl}$ electrolyte," Journal of Electroanalytical Chemistry, 2018.

[22] P. Wang, H. Liu, Y. Xu, Y. Chen, J. Yang, and Q. Tan, "Supported ultrafine ruthenium oxides with specific capacitance up to $1099 \mathrm{~F}$ g- 1 for a supercapacitor," Electrochimica Acta, vol. 194, pp. 211-218, 2016.

[23] I. Deen, X. Pang, and I. Zhitomirsky, "Electrophoretic deposition of composite chitosanhalloysite nanotube-hydroxyapatite films," Colloids and Surfaces A: Physicochemical and Engineering Aspects, vol. 410, pp. 38-44, 2012. 
[24] A. M. Abioye, Z. A. Noorden, and F. N. Ani, "Synthesis and characterizations of electroless oil palm shell based-activated carbon/nickel oxide nanocomposite electrodes for supercapacitor applications," Electrochimica Acta, vol. 225, pp. 493-502, 2017.

[25] A. Pourjavadi, M. Doroudian, A. Ahadpour, and B. Pourbadiei, "Preparation of flexible and free-standing graphene-based current collector via a new and facile self-assembly approach: Leading to a high performance porous graphene/polyaniline supercapacitor," Energy, vol. 152, pp. 178-189, 2018.

[26] S.-Y. Lee, J.-I. Kim, and S.-J. Park, "Activated carbon nanotubes/polyaniline composites as supercapacitor electrodes," Energy, vol. 78, pp. 298-303, 2014.

[27] Q. Wei, X. Tong, G. Zhang, J. Qiao, Q. Gong, and S. Sun, "Nitrogen-doped carbon nanotube and graphene materials for oxygen reduction reactions," Catalysts, vol. 5, pp. 1574-1602, 2015.

[28] A. Yaumi, M. A. Bakar, and B. Hameed, "Reusable nitrogen-doped mesoporous carbon adsorbent for carbon dioxide adsorption in fixed-bed," Energy, vol. 138, pp. 776-784, 2017.

[29] K. Wang, L. Li, T. Zhang, and Z. Liu, "Nitrogen-doped graphene for supercapacitor with longterm electrochemical stability," Energy, vol. 70, pp. 612-617, 2014.

[30] J. Zhao, H. Lai, Z. Lyu, Y. Jiang, K. Xie, X. Wang, et al., "Hydrophilic Hierarchical Nitrogen-Doped Carbon Nanocages for Ultrahigh Supercapacitive Performance," Advanced materials, vol. 27, pp. 3541-3545, 2015.

[31] M. Mirzaeian and P. J. Hall, "The control of porosity at nano scale in resorcinol formaldehyde carbon aerogels," Journal of materials science, vol. 44, pp. 2705-2713, 2009.

[32] R. Pekala, "Organic aerogels from the polycondensation of resorcinol with formaldehyde," Journal of Materials Science, vol. 24, pp. 3221-3227, 1989.

[33] M. Mirzaeian and P. J. Hall, "Nano structure carbons for energy storage in lithium oxygen batteries," in Sustainable Power Generation and Supply, 2009. SUPERGEN'09. International Conference on, 2009, pp. 1-10.

[34] G. Ma, Q. Yang, K. Sun, H. Peng, F. Ran, X. Zhao, et al., "Nitrogen-doped porous carbon derived from biomass waste for high-performance supercapacitor," Bioresource technology, vol. 197, pp. 137-142, 2015.

[35] H. Le and H. Jeong, "Synthesis and Characterization of Nitrogen-doped Activated Carbon by Using Melamine," New Phys, vol. 65, pp. 86-89, 2015.

[36] S. L. Candelaria, B. B. Garcia, D. Liu, and G. Cao, "Nitrogen modification of highly porous carbon for improved supercapacitor performance," Journal of Materials Chemistry, vol. 22, pp. 9884-9889, 2012.

[37] L.-Z. Fan, S. Qiao, W. Song, M. Wu, X. He, and X. Qu, "Effects of the functional groups on the electrochemical properties of ordered porous carbon for supercapacitors," Electrochimica Acta, vol. 105, pp. 299-304, 2013.

[38] T. Lin, I.-W. Chen, F. Liu, C. Yang, H. Bi, F. Xu, et al., "Nitrogen-doped mesoporous carbon of extraordinary capacitance for electrochemical energy storage," Science, vol. 350, pp. 15081513, 2015.

[39] J. Yang, X. Zhou, D. Wu, X. Zhao, and Z. Zhou, "S-Doped N-Rich Carbon Nanosheets with Expanded Interlayer Distance as Anode Materials for Sodium-Ion Batteries," Advanced Materials, vol. 29, p. 1604108, 2017.

[40] W. Li, D. Chen, Z. Li, Y. Shi, Y. Wan, G. Wang, et al., "Nitrogen-containing carbon spheres with very large uniform mesopores: The superior electrode materials for EDLC in organic electrolyte," Carbon, vol. 45, pp. 1757-1763, 2007.

[41] Z. Tian, Y. Qiu, J. Zhou, X. Zhao, and J. Cai, "The direct carbonization of algae biomass to hierarchical porous carbons and CO2 adsorption properties," Materials Letters, vol. 180, pp. 162-165, 2016. 
[42] J. Cai, J. Qi, C. Yang, and X. Zhao, "Poly (vinylidene chloride)-based carbon with ultrahigh microporosity and outstanding performance for $\mathrm{CH} 4$ and $\mathrm{H} 2$ storage and $\mathrm{CO} 2$ capture," ACS applied materials \& interfaces, vol. 6, pp. 3703-3711, 2014.

[43] P. Cheng, T. Li, H. Yu, L. Zhi, Z. Liu, and Z. Lei, "Biomass-derived carbon fiber aerogel as a binder-free electrode for high-rate supercapacitors," The Journal of Physical Chemistry C, vol. 120, pp. 2079-2086, 2016.

[44] W. Li, G. Reichenauer, and J. Fricke, "Carbon aerogels derived from cresol-resorcinolformaldehyde for supercapacitors," Carbon, vol. 40, pp. 2955-2959, 2002.

[45] J. Li, X. Wang, Q. Huang, S. Gamboa, and P. Sebastian, "Studies on preparation and performances of carbon aerogel electrodes for the application of supercapacitor," Journal of Power Sources, vol. 158, pp. 784-788, 2006.

[46] L. Sun, L. Wang, C. Tian, T. Tan, Y. Xie, K. Shi, et al., "Nitrogen-doped graphene with high nitrogen level via a one-step hydrothermal reaction of graphene oxide with urea for superior capacitive energy storage," Rsc Advances, vol. 2, pp. 4498-4506, 2012.

[47] T. Horikawa, N. Sakao, J. i. Hayashi, D. Do, M. Katoh, and K.-I. Sotowa, "Preparation of nitrogen-doped porous carbon and its water adsorption behaviour," Adsorption Science \& Technology, vol. 31, pp. 135-144, 2013.

[48] D. P. Dubal and R. Holze, "All-solid-state flexible thin film supercapacitor based on Mn3O4 stacked nanosheets with gel electrolyte," Energy, vol. 51, pp. 407-412, 2013.

[49] F. Sun, J. Gao, X. Pi, L. Wang, Y. Yang, Z. Qu, et al., "High performance aqueous supercapacitor based on highly nitrogen-doped carbon nanospheres with unimodal mesoporosity," Journal of Power Sources, vol. 337, pp. 189-196, 2017.

[50] M. Yang, Y. Zhong, J. Bao, X. Zhou, J. Wei, and Z. Zhou, "Achieving battery-level energy density by constructing aqueous carbonaceous supercapacitors with hierarchical porous $\mathrm{N}$ rich carbon materials," Journal of Materials Chemistry A, vol. 3, pp. 11387-11394, 2015.

[51] Y. Deng, Y. Xie, K. Zou, and X. Ji, "Review on recent advances in nitrogen-doped carbons: preparations and applications in supercapacitors," Journal of Materials Chemistry A, vol. 4, pp. 1144-1173, 2016.

[52] K. N. Wood, R. O'Hayre, and S. Pylypenko, "Recent progress on nitrogen/carbon structures designed for use in energy and sustainability applications," Energy \& Environmental Science, vol. 7, pp. 1212-1249, 2014.

[53] Z. Li, Z. Xu, H. Wang, J. Ding, B. Zahiri, C. M. Holt, et al., "Colossal pseudocapacitance in a high functionality-high surface area carbon anode doubles the energy of an asymmetric supercapacitor," Energy \& Environmental Science, vol. 7, pp. 1708-1718, 2014.

[54] M. Yang and Z. Zhou, "Recent Breakthroughs in Supercapacitors Boosted by Nitrogen-Rich Porous Carbon Materials," Advanced Science, vol. 4, p. 1600408, 2017.

[55] B. Li, F. Dai, Q. Xiao, L. Yang, J. Shen, C. Zhang, et al., "Nitrogen-doped activated carbon for a high energy hybrid supercapacitor," Energy \& Environmental Science, vol. 9, pp. 102-106, 2016.

[56] L. Sun, C. Tian, Y. Fu, Y. Yang, J. Yin, L. Wang, et al., "Nitrogen-Doped Porous Graphitic Carbon as an Excellent Electrode Material for Advanced Supercapacitors," Chemistry-A European Journal, vol. 20, pp. 564-574, 2014.

[57] Y. Tan, C. Xu, G. Chen, Z. Liu, M. Ma, Q. Xie, et al., "Synthesis of ultrathin nitrogen-doped graphitic carbon nanocages as advanced electrode materials for supercapacitor," ACS applied materials \& interfaces, vol. 5, pp. 2241-2248, 2013.

[58] M. Ren, Z. Jia, Z. Tian, D. Lopez, J. Cai, M. M. Titirici, et al., "High performance N-doped carbon electrodes obtained via hydrothermal carbonization of macroalgae for supercapacitor applications," ChemElectroChem, vol. 5, pp. 2686-2693, 2018.

[59] Z. R. Ismagilov, A. E. Shalagina, O. Y. Podyacheva, A. V. Ischenko, L. S. Kibis, A. I. Boronin, et al., "Structure and electrical conductivity of nitrogen-doped carbon nanofibers," Carbon, vol. 47, pp. 1922-1929, 2009. 
[60] J. D. Wiggins-Camacho and K. J. Stevenson, "Effect of nitrogen concentration on capacitance, density of states, electronic conductivity, and morphology of $\mathrm{N}$-doped carbon nanotube electrodes," The Journal of Physical Chemistry C, vol. 113, pp. 19082-19090, 2009.

[61] V. Arkhipov, P. Heremans, E. Emelianova, and H. Baessler, "Effect of doping on the densityof-states distribution and carrier hopping in disordered organic semiconductors," Physical Review B, vol. 71, p. 045214, 2005.

[62] W. Zhang, Y. Xia, J. Ju, L. Wang, Z. Fang, and M. Zhang, "Electrical conductivity of nitride carbon films with different nitrogen content," Solid state communications, vol. 126, pp. 163166, 2003.

[63] R. Atchudan, T. N. J. I. Edison, S. Perumal, and Y. R. Lee, "Green synthesis of nitrogen-doped graphitic carbon sheets with use of Prunus persica for supercapacitor applications," Applied Surface Science, vol. 393, pp. 276-286, 2017. 


\section{Effect of Nitrogen Doping on the Electrochemical Performance of Resorcinol-}

Formaldehyde Based Carbon Aerogels as Electrode Material for Supercapacitor Applications

Mojtaba Mirzaeian*1, Qaisar Abbas ${ }^{* 1}$, Des Gibson', Michal Mazur ${ }^{2}$

\section{Highlights}

* Nitrogen doped resorcinol/formaldehyde carbon aerogels with controlled nitrogen content are synthesized.

* The contact angle of carbon and $6 \mathrm{M} \mathrm{KOH}$ solution dropped significantly from $123^{\circ}$ to $103^{\circ}$ after nitrogen doping.

* The best specific capacitance of $208 \mathrm{Fg}^{-1}$ is obtained for the carbon doped with nitrogen at an $\mathrm{R} / \mathrm{M}$ ratio of 80 .

* The solution resistance dropped significantly from $0.57 \Omega$ to $0.15 \Omega$ after $\mathrm{N}$ - doping at an $\mathrm{R} / \mathrm{M}$ ratio of 80 .

$\mathrm{R} / \mathrm{M}$ ratio of 80 is the optimum $\mathrm{R} / \mathrm{M}$ ratio at which nitrogen doping results in superior performance of the cell.

Dr Mojtaba Mirzaeian

University of the West of Scotland,

School of Computing, Engineering and Physical Sciences

Paisley, PA1 2BE, UK,

Phone: $+44(0) 1418483567$,

Email: mojtaba.mirazeian@uws.ac.uk 